\title{
Linear low density polyethylene/cycloolefin copolymer blends
}

\author{
A. Dorigato ${ }^{1}$, A. Pegoretti ${ }^{1}$, L. Fambri ${ }^{1}$, C. Lonardi ${ }^{1}$, M. Šlouf ${ }^{2}$, J. Kolařik ${ }^{2}$ \\ ${ }^{1}$ University of Trento, Department of Materials Engineering and Industrial Technologies, via Mesiano 77, 38123 Trento, \\ Italy \\ ${ }^{2}$ Institute of Macromolecular Chemistry, Academy of Sciences of the Czech Republic, v.v.i., Heyrovskeho namesti 2 , \\ 16206 Prague 6, Czech Republic
}

Received 28 June 2010; accepted in revised form 10 September 2010

\begin{abstract}
Linear low density polyethylene (LLDPE) was melt compounded with various amounts of a cycloolefin copolymer (COC). Scanning and transmission electron microscopy evidenced, at qualitative level, some interfacial adhesion between LLDPE and COC. Another indication of interactions between the components was the increase of crystallinity degree with rising COC content and the enhancement of COC glass transition temperature with the LLDPE fraction. In order to explain this behaviour, the incorporation of ethylene segments of COC into the LLDPE crystalline phase, leading to an increased number of norbornene units in the remaining COC component undergoing the glass transition, was hypothesized. The thermo-oxidative degradation stability of LLDPE was substantially enhanced by COC introduction for filler contents higher than $20 \mathrm{wt} \%$, especially when an oxidative atmosphere was considered. An increasing fraction of COC in the blends was responsible for an enhancement of the elastic modulus and of a decrease in the strain at break, while tensile strength passed through a minimum, in agreement with the model predictions based on the equivalent box model and equations provided by the percolation theory. The introduction of a rising COC amount in the blends increased the maximum load sustained by the samples in impact tests, but decreased the blend ductility. Concurrently, a significant reduction of the creep compliance of LLDPE was observed for COC fractions higher than $20 \mathrm{wt} \%$.
\end{abstract}

Keywords: polymer blends and alloys, polyethylene, cycloolefin copolymer, mechanical properties

\section{Introduction}

In the last years a rising scientific and technological interest emerged towards the possibility of mixing two or more polymers, in order to produce new materials, with properties different from those of the parent components [1-4]. Thermoplastic polymers recently synthesized by means of metallocene-based catalysts have attracted the attention of many researchers and producers. Particular interest has been focused on the synthesis and characterization of cycloolefin copolymers (COCs) [5-13], which are amorphous thermoplastics obtained by copolymerization of norbornene and ethylene.
COCs show remarkable properties, such as stiffness, high chemical resistance, good moisture barrier, low moisture absorption and low density. Because of this unique combination of properties, COCs are suitable for the production of transparent mouldings (optical data storage, lenses and sensors), packaging of drugs, medical and diagnostic devices, food containers, etc. As the glass transition temperature $\left(T_{\mathrm{g}}\right)$ of COCs can be adjusted by the percentage of norbornene [14-16], various COC grades suitable for specific applications are available on the market. In order to improve dimensional stability, polyolefinic materials have recently been

\footnotetext{
*Corresponding author: andrea.dorigato@ing.unitn.it
}

(c) BME-PT 
blended with COC. Kolařik et al. prepared and characterized polypropylene (PP)/COC blends $[17$, $18]$ and high-density polyethylene (HDPE)/COC blends $[19,20]$, showing how the COC minority component in form of short fibers or microdomains markedly affects the mechanical properties of the resulting materials. $\mathrm{PP} / \mathrm{COC}$ blends were also prepared by Pimbert [21], finding that the crystallization and nucleation modes of PP seem to be largely influenced by the characteristics of the micro-dispersed phase. Also Šlouf et al. [22] studied PP/COC blends, observing uncommon formation of a fibrous morphology of the minority COC component. Similarly to other thermoplastic brittle polymers, it is also possible to improve the fracture toughness of the pristine $\mathrm{COC}$ by adding small quantities of elastomers. For instance, Stricker et al. [23] studied the influence of polystyrene-block-poly(ethene-co-but1-ene)-block-polystyrene (SEBS) on the mechanical properties of COCs, finding that the notched impact strength of COC was noticeably improved by the addition of SEBS. Furthermore, Khanarian [24] presented a study in which the toughness of COCs was remarkably improved by the addition of small quantities of styrene-butadiene-styrene rubber (SBS), while the original optical transparency was preserved.

Polyethylene is the most widely used commercial thermoplastic, because of its combination of low cost, high chemical resistance and relatively good mechanical properties [25-28]. HDPE is utilized for commodities but also in a variety of high demanding applications such as the production of pipes and fittings for the transportation of water or gas under pressure. On the other hand, low-density polyethylene (LDPE) and linear low-density polyethylene (LLDPE) are mostly used in film production for the packaging industry, because of their high tear and impact strength. LLDPE is a copolymer of ethylene and an $\alpha$-olefin or diene, such as butene, hexene and octene [27], constituted by a linear backbone with little chain branching. Despite all its attributes, LLDPE is not an ideal material for films, where it is most commonly used. In fact LLDPEs polymerized by means of the ZieglerNatta catalysts ( $z$ LLDPE) contain a low-molecularweight extractable component (n-hexane) which accounts for low clarity and low gloss of produced films. LLDPEs synthesized by metallocene cataly- sis ( $m$ LLDPE) show several advantages over $z$ LLDPE, such as higher strength, better optical properties, narrow molecular weight distribution and low extractable fraction. On the other hand, $m$ LLDPE is more difficult to be processed into films [29]. Furthermore, relatively poor creep resistance is considered as one of the main deficiencies of LLDPEs. In fact, in many intended applications, these polymers are often required to sustain long lasting constant loads with limited deformation [30]. In general, the incorporation of fillers in LLDPE increases the elastic modulus of the material and its tensile strength, but often decreases the elongation at break [31]. Thus, mixing LLDPE with a yield- and/or creep-resistant polymer is still an interesting area of materials research. Handge et al. [32] and Liu et al. [33] prepared polystyrene (PS)/ LLDPE blends, while Zhang and coworkers [34, 35] utilized different kinds of organic compatibilizers to enhance the interface adhesion in polyethylene terephthalate (PET)/LLDPE blends. Ismail et al. [36] investigated the processability and miscibility of LLDPE/ polyvinylalcohol (PVA) systems at different blend ratios, finding that the difference in polarity caused very low miscibility of the two components. Su et al. [37] prepared blends of polylactic acid (PLA) and LLDPE in order to investigate the role of the glycidyl methacrylate (GMA)grafted polyethylene-octene copolymer as potential compatibilizer in these systems. Some papers can also be found in literature on the morphology and thermo-mechanical behavior of the LLDPE/rubber blends [38-41]. In general, preparation of such LLDPE based blends may be rather difficult because the compatibility of the polymers will probably be limited [1, 4, 42-44]. Attainment of satisfactory mechanical properties of blends frequently depends on finding a suitable compatibilizer that allows for sufficient interfacial adhesion, finer phase structure, lower tendency to phase structure coarsening, etc $[19,20,45]$. For these reasons, search for 'reinforcing' components imparting better mechanical properties to LLDPE matrices remains a problem to resolve.

Because of a high fraction of ethylene units, $\mathrm{COC}$ is likely to be compatible with polyethylene and other polyolefins without addition of special compatibilizers $[2,17,18,22,46,47]$. Very recently, Lamnawar et al. [48] has investigated the rheological 
and morphological behavior of the LLDPE/COC blends, with particular attention to their peel seal characteristics to films of either PE or PET. Dynamic rheological measurements and scanning electron microscopy techniques confirmed good compatibility of LLDPE and COC with important consequences for the industrial potential of these systems in the production of thin films for packaging applications. To the best of our knowledge, no papers can be found on the correlation between phase structure and the thermo-mechanical properties of the LLDPE/COC blends.

The objective of this work is to prepare LLDPE/ COC blends by melt mixing and to elucidate the effect of morphology and of the physical interactions between the components on the thermomechanical properties of the resulting blends, with particular attention to their creep behavior.

\section{Experimental part}

\subsection{Materials and sample preparation}

Cycloolefin copolymer supplied by Ticona (Kelsterbach, Germany), known under the trade name of Topas ${ }^{\circledR} 8007$ (MFI at $190^{\circ} \mathrm{C}$ and $2.16 \mathrm{~kg}=$ $1.7 \mathrm{~g} \cdot(10 \mathrm{~min})^{-1}$, density $\left.=1.02 \mathrm{~g} \cdot \mathrm{cm}^{-3}\right)$, was melt compounded with a Clearflex ${ }^{\circledR}$ CL106 linear low density polyethylene (density $=0.92 \mathrm{~g} \cdot \mathrm{cm}^{-3}$, MFI at $190^{\circ} \mathrm{C}$ and $\left.2.16 \mathrm{~kg}=3.2 \mathrm{~g} \cdot(10 \mathrm{~min})^{-1}\right)$, kindly provided by Polimeri Europa (Mantova, Italy). Both polymer chips were utilized as received. The samples were prepared through a melt compounding process, by using a Haake Rheomix ${ }^{\circledR} 600$ (Karlsruhe, Germany) internal mixer at $190^{\circ} \mathrm{C}$ for $15 \mathrm{~min}-$ utes at $90 \mathrm{rpm}$, followed by hot pressing at the same temperature in a Carver ${ }^{\circledR}$ (Wabash, IN, USA) laboratory press. In this way, square samples $20 \mathrm{~cm}$ and $0.7 \mathrm{~mm}$ thick were produced. Neat polyethylene and cycloolefin copolymer matrices were denoted respectively as $\mathrm{PE}$ and $\mathrm{COC}$, while the blends were

Table 1. Composition of the prepared PE/COC blends

\begin{tabular}{|l|c|c|}
\hline \multicolumn{1}{|c|}{ Sample } & $\begin{array}{c}\text { COC } \\
\text { weight fraction }\end{array}$ & $\begin{array}{c}\text { COC } \\
\text { volume fraction }\end{array}$ \\
\hline PE & 0 & 0 \\
\hline PE80COC20 & 0.2 & 0.18 \\
\hline PE60COC40 & 0.4 & 0.38 \\
\hline PE50COC50 & 0.5 & 0.47 \\
\hline PE40COC60 & 0.6 & 0.58 \\
\hline PE20COC80 & 0.8 & 0.78 \\
\hline COC & 1.0 & 1.00 \\
\hline
\end{tabular}

designated with the weight fractions of $\mathrm{PE}$ and COC. For instance, PE80COC20 indicates a sample constituted by $80 \mathrm{wt} \%$ of $\mathrm{PE}$ and $20 \mathrm{wt} \%$ of COC (Table 1).

\subsection{Experimental techniques}

The morphology of the prepared samples was investigated by electron microscopy techniques. SEM images of the fracture surfaces of the blends were taken by using a Jeol JSM 6400 (Tokyo, Japan) microscope. The samples were fractured in liquid nitrogen and observed after a sputtering process with platinum. STEM images were collected by a Vega TS 5130 (Brno, Czech Republic) microscope. Thin sections of the samples were ultramicrotomed at $-130^{\circ} \mathrm{C}$ and stained with $\mathrm{RuO}_{4}$ vapors before the observations.

DSC tests were conducted by using a Mettler DSC30 (Schwerzenbach, Switzerland) calorimeter, under a nitrogen flow of $100 \mathrm{ml} \cdot \mathrm{min}^{-1}$. The samples were heated from 0 to $200^{\circ} \mathrm{C}$ at $10^{\circ} \mathrm{C} \cdot \mathrm{min}^{-1}$ and then cooled down to $0^{\circ} \mathrm{C}$ at the same rate. A second heating run up to $200^{\circ} \mathrm{C}$ was then carried out under the same conditions as the first run. In this way it was possible to evaluate the melting temperature of $\mathrm{PE}$ in the blends and its crystallinity $\left(X_{\mathrm{PE}}\right)$, computed as the ratio of the melting enthalpy $\left(\Delta H_{\mathrm{m}}\right)$, normalized for the effective weight fraction of LLDPE in the blends $(f)$, and the reference value of the fully crystalline polyethylene $\left(\Delta H_{0}\right)$, taken as $293.6 \mathrm{~J} \cdot \mathrm{g}^{-1}$ [49], as reported in Equation (1):

$X_{\mathrm{PE}}=100 \cdot \frac{\Delta H_{\mathrm{m}}}{\Delta H_{0} \cdot f}$

Thermogravimetric analysis (TGA) was conducted by using a Mettler TG50 (Schwerzenbach, Switzerland) thermobalance from 30 to $600^{\circ} \mathrm{C}$ at a heating rate of $10^{\circ} \mathrm{C} \cdot \mathrm{min}^{-1}$. Various atmospheres were used (nitrogen, air, oxygen), keeping a constant flow of $150 \mathrm{ml} \cdot \mathrm{min}^{-1}$. The temperatures associated to a mass loss of $2 \%\left(T_{2} \%\right)$ and of $5 \%\left(T_{5 \%}\right)$, and the maximum mass loss rate temperature $\left(T_{\mathrm{d}}\right)$ were determined on the TGA plots. Dynamic mechanical thermal analysis (DMTA) test was carried out under tensile configuration with a MkII Polymer Laboratories (Loughborough, UK) analyzer, in the temperature range from -135 to $130^{\circ} \mathrm{C}$ at a heating rate of $3^{\circ} \mathrm{C} \cdot \mathrm{min}^{-1}$. A sinusoidal displacement with a peak- 
to-peak amplitude of $64 \mu \mathrm{m}$ and a frequency of $1 \mathrm{~Hz}$ was imposed to the samples.

Quasi-static uniaxial tensile tests were performed with an Instron 4502 (Norwood, MA, USA) testing machine, equipped with a $1 \mathrm{kN}$ load cell, on ISO 527-1BA samples, having a gage length of $30 \mathrm{~mm}$ and a width of $5 \mathrm{~mm}$. Tensile tests up to break were performed at a crosshead speed of $50 \mathrm{~mm} \cdot \mathrm{min}^{-1}$ ( strain rate $\left.=167 \% \cdot \mathrm{min}^{-1}\right)$. At least five specimens for each blend sample were tested. In order to evaluate more accurately the deformation of the samples, tensile tests for the determination of the elastic modulus were conducted at a lower speed $\left(0.25 \mathrm{~mm} \cdot \mathrm{min}^{-1}\right)$, and the strain was monitored by an Instron 2620-601 (Norwood, MA, USA) clip-on resistance extensometer, with a gage length of $12.5 \mathrm{~mm}$ (strain rate $=2 \% \cdot \mathrm{min}^{-1}$ ). According to ISO 527 standard, the elastic modulus of the blends $\left(E_{\mathrm{b}}\right)$ was determined on at least five specimens as a secant value between the strain levels of 0.05 and of $0.25 \%$.

Tensile impact tests were conducted on ISO 5271BA specimens with a CEAST (Turin, Italy) instrumented impact pendulum using a striker mass of $3.65 \mathrm{~kg}$ and an impact speed of $1.25 \mathrm{~m} \cdot \mathrm{s}^{-1}$ (with an overall impact energy of about $2.85 \mathrm{~J}$ ). Also in this case five specimens were tested for each sample.

Isothermal creep tests were carried out at $30^{\circ} \mathrm{C}$ by an Instron 4502 (Norwood, MA, USA) testing machine. In order to avoid problems related to the precise determination of the effective gage length and to measure with more accuracy the creep strain, rectangular samples, $100 \mathrm{~mm}$ long, $5 \mathrm{~mm}$ wide and $0.7 \mathrm{~mm}$ thick, with a gage length of $60 \mathrm{~mm}$, were utilized. Each sample was tested imposing different stress levels $\left(\sigma_{0}\right)$, ranging from 20 to $60 \%$ of the yield strength, for a total duration of 1 hour. Tensile creep compliance $D(t)$ was computed by dividing the time dependent strain $\varepsilon(t)$ by the constant stress $(\sigma)$. Isochronous stress-strain curves were then constructed considering the strain of the specimens at different creep stresses at selected times between 600 and $3600 \mathrm{~s}$.

\subsection{Theoretical background}

The equivalent box model (EBM) combined with the percolation approach to the phase continuity was utilized to predict the modulus and the stress at break of the polymer blends under investigation.

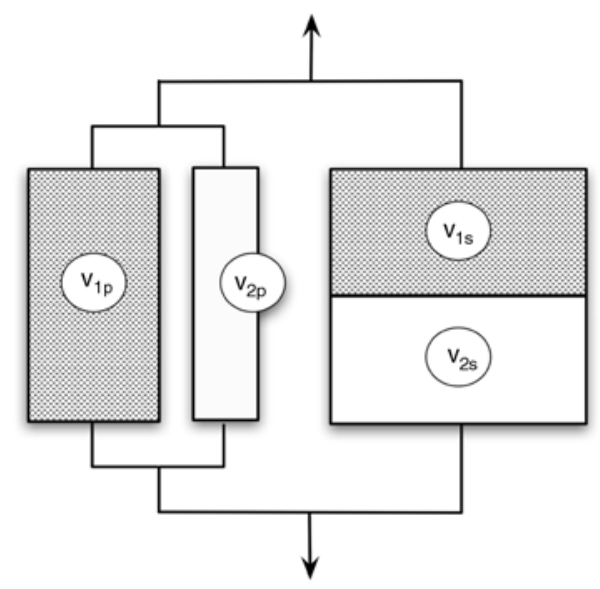

Figure 1. Schematic representation of the equivalent box model (EBM)

Generally speaking, polymer blends are heterogeneous isotropic materials with three-dimensional continuity of one or more components. For this reason, simple parallel or series models or the models for orthotropic or quasi-isotropic materials are not applicable [50]. In our previous paper [18], the predictive capacity of the modified EBM was successfully verified.

The EBM (Figure 1) operates with partly parallel (subscript $p$ ) and partly series (subscript $s$ ) couplings of two components. This EBM is a two-parameter model as of four volume fractions $\left(v_{\mathrm{ij}}\right)$ only two are independent variables. The volume fractions are interrelated as reported in Equation (2a) and Equation (2b):

$v_{1}=v_{1 \mathrm{p}}+v_{1 \mathrm{~s}}$

$v_{2}=v_{2 p}+v_{2 \mathrm{~s}}$

where $v_{1}+v_{2}=v_{\mathrm{p}}+v_{\mathrm{s}}=1$. The blocks in the EBM are presumed to have physical properties of the neat components. For this reason the EBM is likely to fail if the mixing process produces significant changes in the structure and properties of the blend components. As the EBM is not a self-consistent model, the predictive format requires two steps: the derivation of the equations for the properties under consideration and the calculation of the volume fractions $\left(v_{\mathrm{ij}}\right)$ by using equations rendered by the percolation theory [51-53]. Elastic moduli of the parallel $\left(E_{\mathrm{p}}\right)$ and series $\left(E_{\mathrm{s}}\right)$ branches of the EBM can be computed as indicated in Equation (3a) and in Equation (3b):

$E_{\mathrm{p}}=\frac{E_{1} v_{1 \mathrm{p}}+E_{2} v_{2 \mathrm{p}}}{v_{\mathrm{p}}}$ 


$$
E_{s}=\frac{v_{\mathrm{s}}}{\frac{v_{1 \mathrm{~s}}}{E_{1}}+\frac{v_{2 \mathrm{~s}}}{E_{2}}}
$$

The resulting tensile modulus of two-component systems $\left(E_{\mathrm{b}}\right)$ is then given as reported in Equation (4):

$$
E_{\mathrm{b}}=E_{\mathrm{p}} v_{\mathrm{p}}+E_{\mathrm{s}} v_{\mathrm{s}}=E_{1} v_{1 \mathrm{p}}+E_{2} v_{2 \mathrm{p}}+\frac{v_{\mathrm{s}}^{2}}{\frac{v_{1 \mathrm{~s}}}{E_{1}}+\frac{v_{2 \mathrm{~s}}}{E_{2}}}
$$

The tensile stress at break $\left(\sigma_{\mathrm{b}}\right)$ of blends obeys the following expression (Equation (5)), derived in terms of the EBM $[50,54]$ :

$\sigma_{\mathrm{b}}=\sigma_{\mathrm{b} 1} \cdot v_{1 \mathrm{p}}+\sigma_{\mathrm{b} 2} \cdot v_{2 \mathrm{p}}+A \cdot \sigma_{\mathrm{b} 1} \cdot v_{\mathrm{s}}$

where $\sigma_{\mathrm{b} 1}$ or $\sigma_{\mathrm{b} 2}$ denotes the tensile stress at break of the components, while $A$ is a parameter correlated to the extent of interfacial debonding $(0 \leq$ $A \leq 1)$. Two limiting values of $\sigma_{\mathrm{b}}$ can be distinguished by means of Equation (5). If $A=0$, the interfacial adhesion is so weak that complete debonding occurs before the fracture of the component fractions coupled in series. Consequently, as a function of blend composition, $\sigma_{\mathrm{b}}$ passes through a minimum. If $A=1$, interfacial adhesion is strong enough to transmit the acting stress between constituents so that no debonding appears during the fracture process, and the contribution of the series branch in the EBM is added to that of the parallel branch. In this case $\sigma_{\mathrm{b}}$ is a monotonic function of the blend composition. Employing the universal formula provided by the percolation theory for the elastic modulus of binary systems, Kolařik and coworkers derived Equation (6a) and Equation (6b) for $v_{\mathrm{ij}}[55-59]$ :

$v_{1 \mathrm{p}}=\left(\frac{v_{1}-v_{1 \mathrm{cr}}}{1-v_{1 \mathrm{cr}}}\right)^{\mathrm{q}}$

$v_{2 \mathrm{p}}=\left(\frac{v_{2}-v_{2 \mathrm{cr}}}{1-v_{2 \mathrm{cr}}}\right)^{\mathrm{q}}$

where $v_{1 \text { cr }}$ or $v_{2 \text { cr }}$ is the critical volume fraction (the percolation threshold) at which the component 1 or 2 becomes partially continuous and $q$ is the critical exponent. In the marginal zone $\left(0<v_{1}<v_{1 \mathrm{cr}}\right.$ or $0<v_{2}<v_{2 c r}$ ), where only one component is continuous, the proposed format cannot be utilized. For approximate calculations, simplified relations can be used for the minority component, i.e. $v_{1 \mathrm{p}}=0$ and $v_{1 \mathrm{~s}}=v_{1}\left(\right.$ or $v_{2 \mathrm{p}}=0$ and $\left.v_{2 \mathrm{~s}}=v_{2}\right)$. Most ascertained values of $q$ are located in an interval between 1.6 and 2.0 , so that $q=1.8$ can be used as an average value. For the three-dimensional cubic lattice, the percolation threshold $v_{\mathrm{cr}}=0.156$ was determined [51-53].

As tested materials displayed nonlinear viscoelastic behavior, the effect of rising strain on the creep compliance of the samples was accounted for through a modification of the original time-strain superposition principle [60, 61]. Starting from the fact that higher stresses accelerate creep of nonlinear viscoelastic materials, the time - stress superposition principle has been proposed to analyze the isothermal creep behavior of the prepared blends in a wider time scale [62-65]. In other words, creep compliance curves computed at different stress levels $(\sigma)$ can be shifted along the time scale to construct a creep compliance master curve in a wider time scale at a constant temperature $\left(T_{0}\right)$ and at a reference stress level $\left(\sigma_{0}\right)$, through the introduction of a stress-dependent shift factor $\left(a_{\sigma}\right)$, as reported in Equation (7):

$D(\sigma, \log t)=D\left(\sigma_{0}, \log t-\log a_{\sigma}\right)$

Stress-dependent shift factor values can be determined as indicated in Equation (8):

$\log a_{\sigma}=-\frac{C_{1}\left(\sigma-\sigma_{0}\right)}{C_{2}+\left(\sigma-\sigma_{0}\right)}$

where the constants $C_{1}$ and $C_{2}$, related to the fractional free volume, can be determined a posteriori by fitting shift factor data determined at different stress levels.

\section{Results and discussion}

\subsection{Microstructure characterization}

It is well known that physical properties of polymer blends are closely related to their phase structure. In STEM micrographs (Figure 2), the dark component corresponds to $\mathrm{COC}$, while the bright one represents PE. From a general point of view, at volume fractions lower than $0.15-0.20$ the minority component in immiscible blends forms spherical particles (in studied blends the mean diameter is smaller than $5 \mu \mathrm{m}$ ) uniformly dispersed in the majority component. Considering PE20COC80 sample, it is evident that LLDPE is well dispersed in COC in form of microspheres having a mean diameter of about 


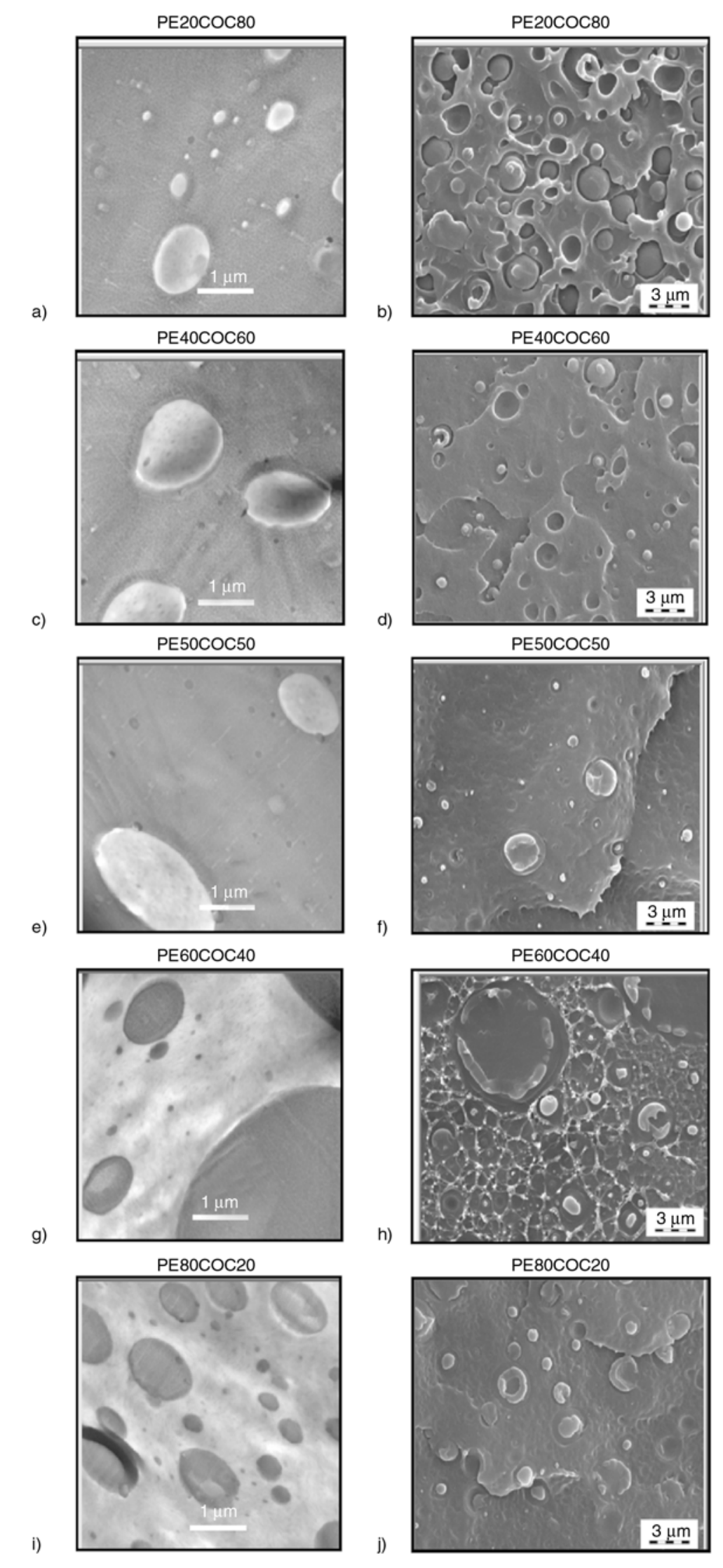

Figure 2. STEM micrographs (left column, pictures a, c, e, g, i) and SEM micrographs (right column, pictures b, d, f, h, j) of the PE/COC blends 
$0.5 \mu \mathrm{m}$. Some debonding, probably produced during the sample microtoming, can be detected around polyethylene particles. The phase inversion takes place in the blends with 40 to $60 \mathrm{wt} \%$ of LLDPE. SEM micrographs of PE40COC60, PE50COC50, PE60COC40 and PE80COC20 blends indicate quite high interfacial adhesion between the components, because the fracture frequently propagates through the particles of the minority phase and not along the LLDPE/COC interphase. This supports the hypothesis of a partial component miscibility in the LLDPE/COC blends, as originally advanced by Lamnawar et al. [48]. In fact, these authors indicated a partial phase miscibility by means of the Cole-Cole and equivalent plots of the dynamic rheological properties, which was subsequently confirmed by scanning electron microscopy. For the blends with low COC fractions $(20 \mathrm{wt} \%)$, the microstructure is characterized by small microspheres of $\mathrm{COC}$ with a mean diameter of $0.5 \mu \mathrm{m}$ and narrow size distribution.

\subsection{Calorimetric and dynamic mechanical characterizations}

Figure 3 reports DSC thermograms of the neat components and corresponding blends while the most relevant thermal properties are summarized in

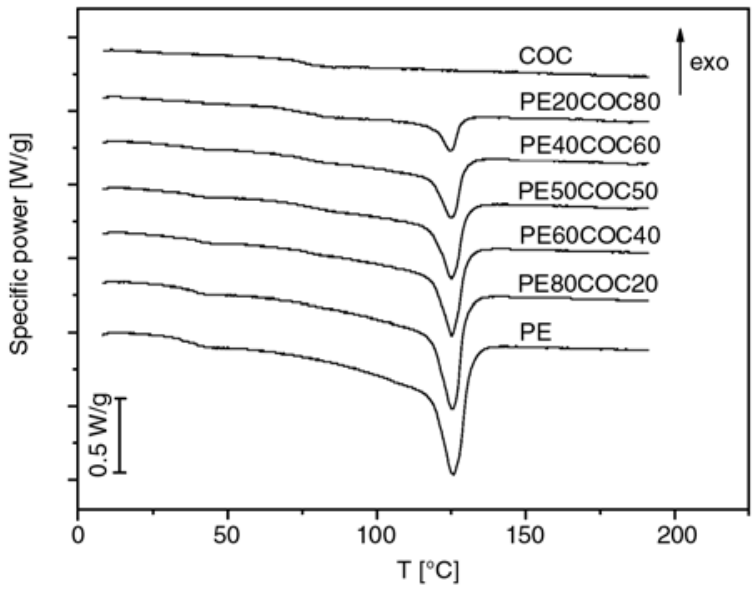

Figure 3. DSC thermograms of the PE/COC blends (first scan)

Table 2. As expected, the intensity of the endothermic peak associated to the melting of the crystalline regions of PE increases with the PE fraction in the blends, while the signal associated to the glass transition of the COC component at about $70^{\circ} \mathrm{C}$ is too weak to be quantitatively analyzed. The melting temperature of PE (Table 2) is not affected by the presence of $\mathrm{COC}$, while the crystallinity degree of $\mathrm{PE}$ increases with the COC content in the blends. It can be tentatively hypothesized that a partial cocrystallization of the ethylene segments of COC may take place along with the crystallization of PE.

Table 2. Results obtained from DSC tests of the PE/COC blends

\begin{tabular}{|c|c|c|c|c|c|c|}
\hline \multirow{2}{*}{ Sample } & \multicolumn{2}{|c|}{ PE melting temperature $\left[{ }^{\circ} \mathrm{C}\right]$} & \multicolumn{2}{|c|}{ PE melting enthalpy $[\mathrm{J} / \mathrm{g}]$} & \multicolumn{2}{|c|}{ PE crystallinity [\%] } \\
\hline & $1^{\text {st }}$ scan & $2^{\text {nd }}$ scan & $1^{\text {st }}$ scan & $2^{\text {nd }}$ scan & $1^{\text {st }}$ scan & $2^{\text {nd }}$ scan \\
\hline $\mathrm{PE}$ & 125.4 & 125.3 & 81.1 & 87.5 & 27.6 & 29.8 \\
\hline PE80COC20 & 125.5 & 125.4 & 73.1 & 73.9 & 31.1 & 31.5 \\
\hline PE60COC40 & 125.1 & 125.0 & 50.4 & 55.7 & 28.6 & 31.6 \\
\hline PE50COC50 & 125.1 & 125.1 & 47.7 & 47.5 & 32.5 & 32.4 \\
\hline PE40COC60 & 124.6 & 124.5 & 39.4 & 40.7 & 33.6 & 34.7 \\
\hline PE20COC80 & 124.9 & 124.9 & 24.3 & 23.3 & 41.4 & 39.7 \\
\hline
\end{tabular}
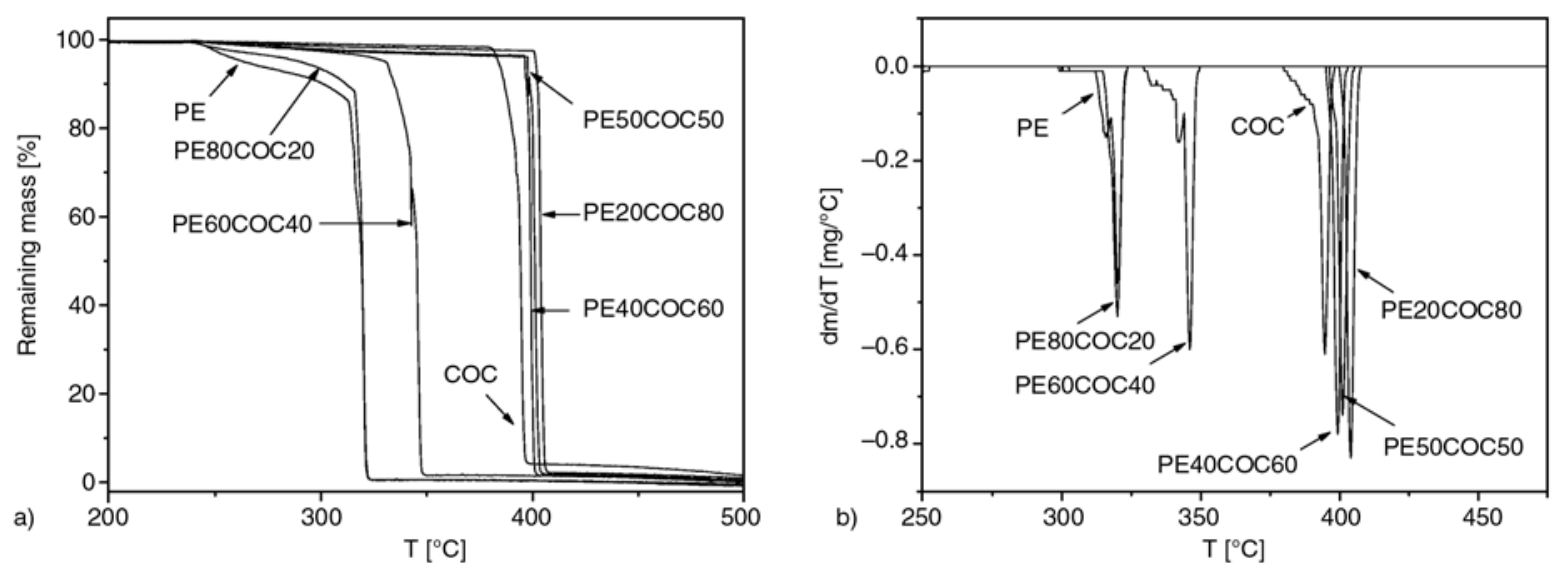

Figure 4. TGA tests of the PE/COC blends. Representative thermogravimetric curves (a) and derivative of the mass loss curves (b) under oxygen atmosphere 
However, further investigations would be necessary to explain the observed increase of the LLDPE crystallinity due to the COC addition.

Representative thermogravimetric curves of the prepared blends under oxygen atmosphere are given in Figure $4 \mathrm{a}$, while plots of the derivative of the mass loss curves with temperature are reported in Figure 4b. Although thermogravimetric curve of the PE80COC20 blend is very similar to that of the neat polyethylene, notable enhancements of the thermal degradation resistance, documented by a progressive increase of $T_{2 \%}, T_{5 \%}$ and $T_{\mathrm{d}}$ values, can be detected for the blends with the COC fractions higher than $40 \mathrm{wt} \%$ (Figure 5). Comparing thermogravimetric curves under different atmospheres, it is evident that the improvements due to the introduction of COC are more pronounced in oxygen atmosphere. For example, $T_{2} \%$ of the PE20COC 80 blend is about $100^{\circ} \mathrm{C}$ higher than that of the neat $\mathrm{PE}$ matrix. As reported in literature [66, 67], it is probable that the presence of a second component with higher thermal stability limits the diffusion of the oxygen through the sample, thus delaying the degradation process of the PE component.

For as concerns DMTA tests, storage modulus $\left(E^{\prime}\right)$ of the blends at different temperatures and the glass transition temperature $\left(T_{\mathrm{g}}\right)$ of the COC component, evaluated from $\tan \delta$ peaks, are summarized in Table 3. At temperatures below the glass transition of $\mathrm{PE}$ (i.e. about $-130^{\circ} \mathrm{C}$ ) $E^{\prime}$ is slightly affected by the fraction of COC. On the other hand, at 25 and $50^{\circ} \mathrm{C}$ the increasing fraction of the stiffer COC component leads to a remarkable enhancement of the storage modulus. Another interesting feature is that $T_{\mathrm{g}}$ of the COC component slightly increases with the PE fraction in the blends. The presence of clearly separated glass transitions of the parent components indicates the formation of phase-separated blends (as confirmed by SEM and STEM images). However, the fine micron scale morphology obtained through melt blending may affect individual component transitions, such as crystallization and glass transition, through interphase physical interactions [68]. In fact, Thirta et al. [68, 69] showed that the $T_{\mathrm{g}}$ of polystyrene (PS) blended with polypropylene (PP) or PE was increased with decreasing PS percentage in the blends. The enhancement of the $T_{\mathrm{g}}$ of PS in PS/PP and PS/PE blends was attributed to two possible reasons:
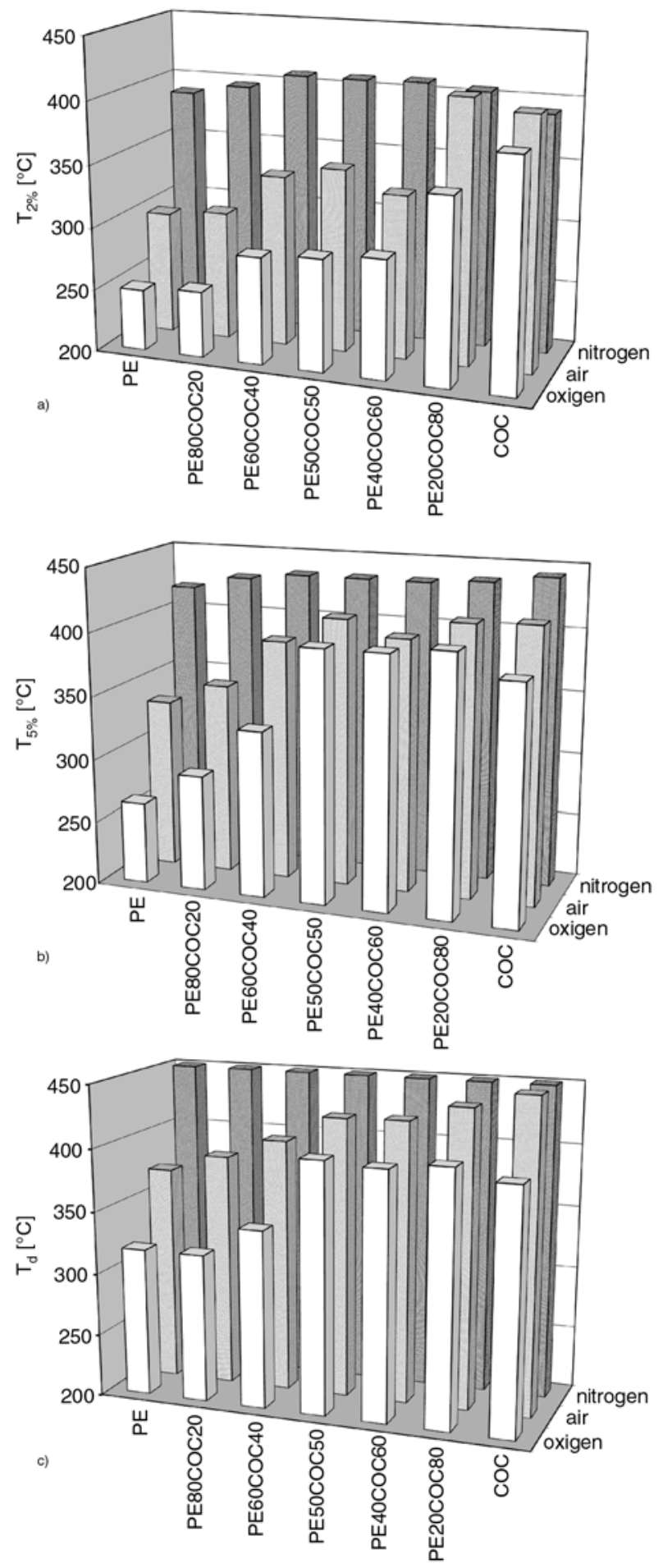

Figure 5. Results of TGA tests of the PE/COC blends under different atmospheres. (a) $T_{2 \%}$, (b) $T_{5 \%}$, (c) $T_{\mathrm{d}}$

i) compressive pressure exerted on the amorphous PS domains due to differential shrinkage between the amorphous PS and crystallizing phases, and ii) immobilization of the polymer interfacial layer at the domain boundaries in a process similar to that observed in filled composite systems. In addition we could suppose another possible cause related to 
Table 3. Storage modulus $\left(E^{\prime}\right)$ at different temperatures and glass transition temperature $\left(T_{\mathrm{g}}\right)$ of the COC component from DMTA tests of the PE/COC blends

\begin{tabular}{|c|c|c|c|c|c|}
\hline \multirow{2}{*}{ Sample } & \multicolumn{4}{|c|}{$\mathbf{E}^{\prime}$ [MPa] } & \multirow{2}{*}{$\mathbf{T}_{\mathrm{g}} \mathbf{C O C}\left[{ }^{\circ} \mathrm{C}\right]$} \\
\hline & $-130^{\circ} \mathrm{C}$ & $25^{\circ} \mathrm{C}$ & $5^{\circ}{ }^{\circ} \mathrm{C}$ & $90^{\circ} \mathrm{C}$ & \\
\hline $\mathrm{PE}$ & 2349 & 180 & 64 & 4 & - \\
\hline PE80COC20 & 3296 & 477 & 243 & 34 & 86.5 \\
\hline PE60COC40 & 3295 & 671 & 334 & 20 & 86.0 \\
\hline PE50COC50 & 2988 & 752 & 379 & 14 & 85.4 \\
\hline PE40COC60 & 2969 & 1176 & 851 & 15 & 84.1 \\
\hline PE20COC 80 & 2570 & 1393 & 1289 & 4 & 83.5 \\
\hline $\mathrm{COC}$ & 2713 & 1860 & 1760 & 3 & 82.6 \\
\hline
\end{tabular}

a partial incorporation of the ethylene segments of COC into PE crystalline phase. The remaining amorphous segments of the COC component will thus contain higher percentage of norbornene units, which may account for a lower backbone flexibility and, consequently, a higher $T_{\mathrm{g}}$.

\subsection{Tensile mechanical behaviour}

Table 4 reports elastic modulus values of the $\mathrm{PE} / \mathrm{COC}$ blends from quasi-static tensile tests, while in Figure 6 experimental data are compared with the theoretical prediction provided by the equivalent box model. In agreement with the existing literature [18-20, 56, 57], the introduction of a stiffer component accounts for an increase in the elastic modulus of the blends. The elastic modulus increase in the PE/COC blends is less pronounced for COC fractions smaller than $50 \%$, while for its higher fractions a strong enhancement can be detected due to increasing phase continuity of the COC component in the blends. Also in this case, the data estimated by the EBM approach plausibly fit the experimental data over the whole range of investigated compositions.

In Figure 7a selected stress-strain curves illustrating the quasi-static tensile behaviour of the investigated blends are given. Neat PE and the PE80COC20 blend show an elasto-plastic behaviour with relatively low yield strength (about $10 \mathrm{MPa}$ ) and high strain at break (around 1500\%).

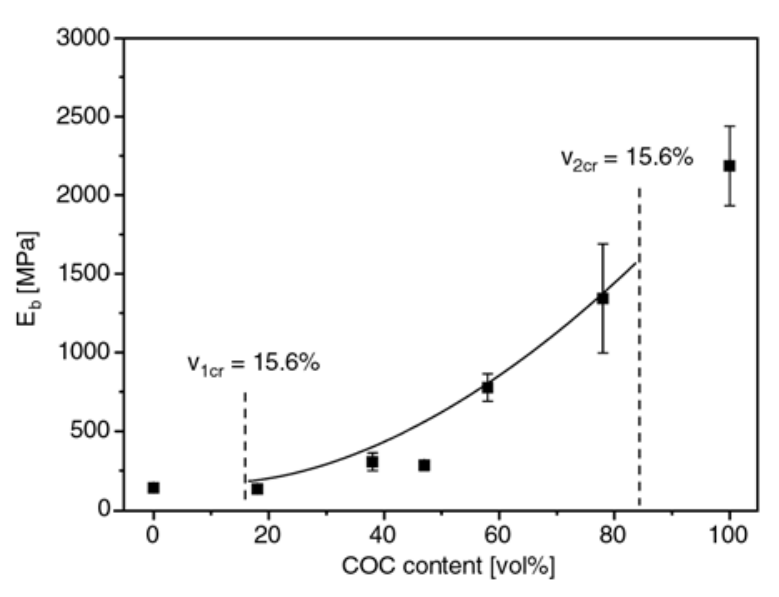

Figure 6. Elastic modulus of the PE/COC blends from quasi-static tensile tests and the theoretical prediction (continuous line) according to the equivalent box model (EBM)

For higher COC fractions, a pronounced reduction of the strain at break accompanied by an increase in yield strength can be observed. Neat COC matrix displays a rather brittle behaviour, typical of amorphous thermoplastics below their glass transition temperature. Interestingly enough, Figure $7 \mathrm{~b}$ shows that also stress at break can be successfully fitted over the whole range of investigated compositions utilizing the equivalent box model. It is generally believed that the presence of a minimum on the tensile strength vs. blend composition dependence indicates poor interfacial adhesion between the components [50]. Considering Equation (5), the $A$

Table 4. Results of quasi-static tensile tests of the PE/COC blends, with the determination of the brittleness of the samples $(B)$ according to Equation (9)

\begin{tabular}{|l|c|c|c|c|c|}
\hline \multicolumn{1}{|c|}{ Sample } & $\mathbf{E}[\mathbf{M P a}]$ & $\boldsymbol{\sigma}_{\mathbf{y}}[\mathbf{M P a}]$ & $\boldsymbol{\sigma}_{\mathbf{b}}[\mathbf{M P a}]$ & $\mathbf{1 0}$ & $\boldsymbol{\varepsilon}_{\mathbf{b}}[\mathbf{\%}]$ \\
\hline PE & $140 \pm 121$ & $10.4 \pm 0.1$ & $25.2 \pm 1.6$ & $1540 \pm 64$ \\
\hline PE80COC20 & $133 \pm 12$ & $10.9 \pm 0.1$ & $17.7 \pm 1.4$ & $1210 \pm 92$ \\
\hline PE60COC40 & $305 \pm 56$ & $15.2 \pm 0.8$ & $14.1 \pm 0.6$ & $20 \pm 6$ \\
\hline PE50COC50 & $283 \pm 32$ & $16.6 \pm 0.8$ & $15.9 \pm 1.2$ & $11 \pm 3$ \\
\hline PE40COC60 & $777 \pm 87$ & $25.5 \pm 1.6$ & $25.3 \pm 1.6$ & 0.017 \\
\hline PE20COC80 & $1343 \pm 346$ & $35.1 \pm 3.6$ & $25.8 \pm 1.7$ & $22 \pm 8$ \\
\hline COC & $2185 \pm 252$ & - & $56.2 \pm 0.6$ & 1.209 \\
\hline
\end{tabular}



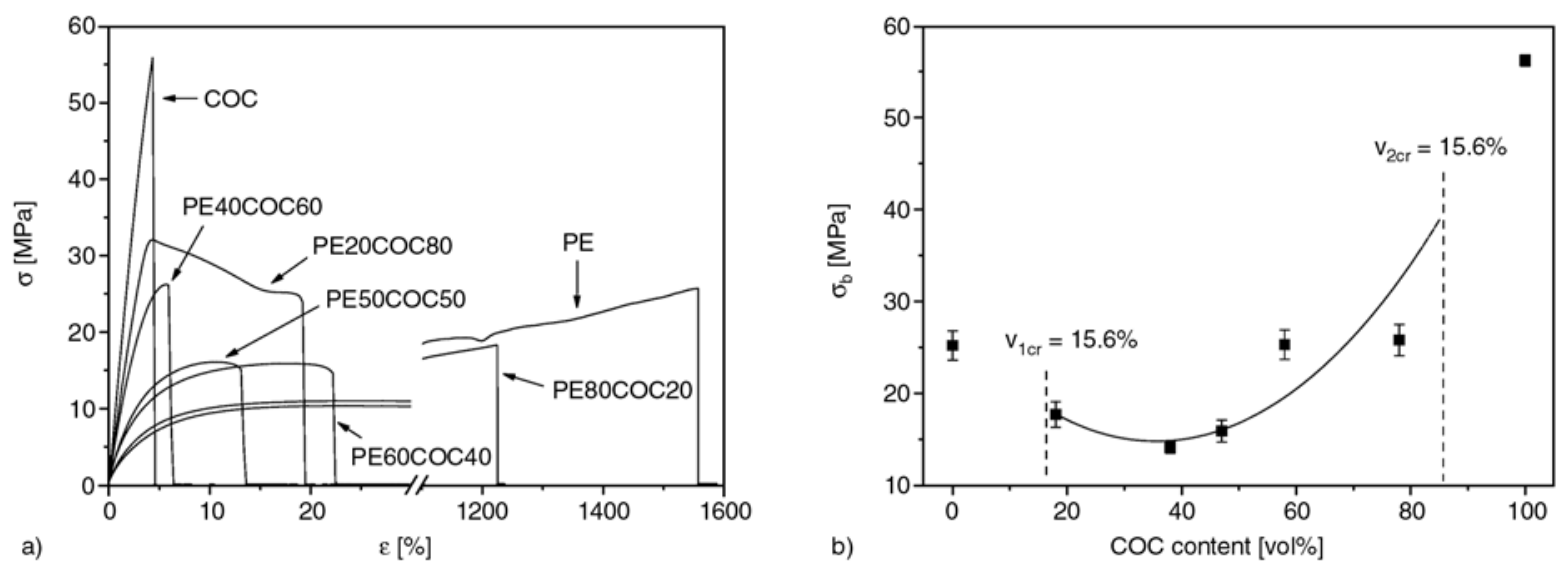

Figure 7. (a) Representative stress-strain curves from quasi-static tensile tests of the PE/COC blends, (b) stress at break values and theoretical prediction (continuous line) according to the equivalent box model (EBM) $(A=0.04)$

value, for which the fitting of the stress at break data is performed, is proportional to the quality of the interfacial adhesion between the two phases. In the present case an $A$ value near to zero (0.04) was adopted, which indicates a limited interfacial adhesion between LLDPE and COC. In order to quantitatively describe the embrittlement due to $\mathrm{COC}$ introduction, a brittleness $(B)$ parameter was introduced by Brostow et al. [70, 71], as reported in Equation (9):

$B=\frac{1}{\varepsilon_{\mathrm{b}} \cdot E^{\prime}}$

where $\varepsilon_{\mathrm{b}}$ is the strain at break from quasi-static tensile tests and $E^{\prime}$ is the storage modulus at $25^{\circ} \mathrm{C}$ obtained from DMTA tests. As reported in Table 4, it can be seen that $B$ values generally increase with the COC amount, passing from $0.036 \cdot 10^{-10}(\% \cdot \mathrm{Pa})^{-1}$ for the neat LLPDE to $1.34 \cdot 10^{-10}(\% \cdot \mathrm{Pa})^{-1}$ for the neat $\mathrm{COC}$ matrix. It is important to underline that the obtained values are very near to that reported in literature references for similar polymeric matrices [70, 71].

Representative force-displacement curves obtained under tensile impact conditions are reported in Figure 8 and the most important results are summarized in Table 5. Increasing fraction of $\mathrm{COC}$ in blends progressively increases the maximum load sustained by the samples, but decreases the ductility. For example, specific tensile energy to break (TEB) of PE80COC20 sample is about seven times lower than that of neat PE. It can be hypothesized that due to poor interfacial adhesion the COC particles embedded in PE matrix act as crack initiating

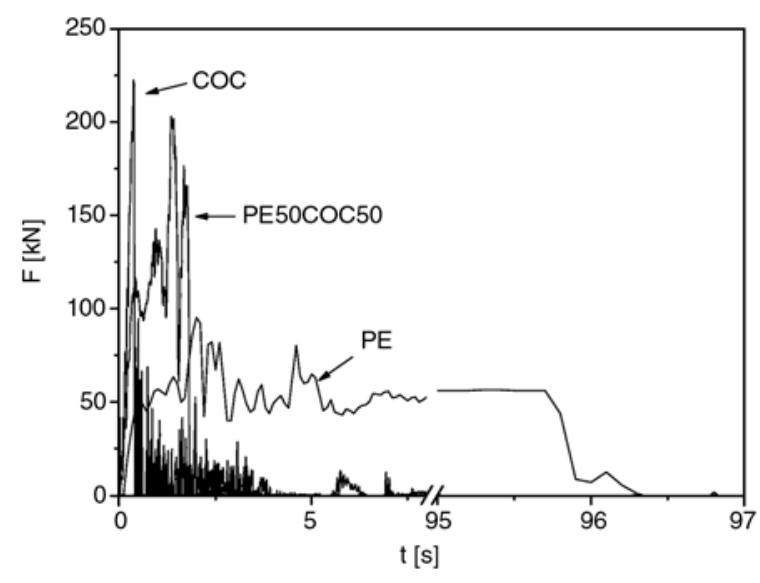

Figure 8. Representative curves of tensile impact tests of the PE/COC blends

Table 5. Results of tensile impact tests of the PE/COC blends

\begin{tabular}{|l|c|c|c|}
\hline \multicolumn{1}{|c|}{ Sample } & $\mathbf{F}_{\max }[\mathbf{N}]$ & $\boldsymbol{\varepsilon}_{\mathbf{b}}[\mathbf{\%} \mathbf{]}$ & $\mathbf{T E B}\left[\mathbf{J} / \mathbf{m m}^{\mathbf{2}}\right]$ \\
\hline PE & $99 \pm 4$ & $852 \pm 126$ & $5.38 \pm 0.71$ \\
\hline PE80COC20 & $121 \pm 5$ & $105 \pm 30$ & $0.76 \pm 0.16$ \\
\hline PE60COC40 & $166 \pm 12$ & $50 \pm 9$ & $0.46 \pm 0.08$ \\
\hline PE50COC50 & $206 \pm 5$ & $21 \pm 2$ & $0.23 \pm 0.03$ \\
\hline PE40COC60 & $152 \pm 6$ & $11 \pm 1$ & $0.12 \pm 0.02$ \\
\hline PE20COC80 & $207 \pm 6$ & $8 \pm 2$ & $0.11 \pm 0.04$ \\
\hline COC & $231 \pm 12$ & $4 \pm 1$ & $0.05 \pm 0.01$ \\
\hline
\end{tabular}

sites. On the other hand, weakly bonded PE microspheres dispersed in the COC matrix may induce a toughening effect similar to that reported for rubber toughened thermoplastics $[23,24]$.

\subsection{Creep behaviour}

Isothermal creep compliance curves of neat $\mathrm{PE}$ at $30^{\circ} \mathrm{C}$ obtained at different stress levels (ranging from 20 to $60 \%$ of the yield strength) are reported in Figure 9a, while in Figure 9b isochronous curves 
at different times (from 600 to $3600 \mathrm{~s}$ ) are given. As generally known, an enhancement of the applied stress produces a noticeable increase in the creep compliance of semicrystalline polymers above their glass transition temperature [72]. This nonlinear viscoelastic effects have been associated to a straininduced increase in the free volume in the amorphous phase of the material [17, 20, 46, 72]. From the analysis of the isochronous curves it is evident that the apparent linearity limit can be registered at strain levels of less than $5 \%$.

Isochronous curves at $3600 \mathrm{~s}$ of neat components and of the relative blends as obtained from isothermal creep tests are compared in Figure 10. The introduction of small amounts of COC (up to $20 \mathrm{wt} \%$ ) in the PE matrix does not substantially affect the creep behaviour of the resulting blend, because the creep-resistant COC component is fully discontinuous (Figure 10). For higher COC fractions, a progressive improvement of the creep resistance can be detected. Analogously, the creep behaviour of PE20COC80 blends is very similar to that of the neat COC matrix. Figure 10b indicates that PE and PE80COC20 samples do not show the apparent linear viscoelastic behaviour even at relatively small strains. In contrast, the creep compliance of COC and PE20COC 80 blend seems to be practically stress independent over the whole range of considered stress, which is typical for thermoplastic materials below their glass transition temperature.

The effect of the COC fraction on the stress dependent creep behaviour of the prepared blends can be evaluated on a longer time scale by constructing creep compliance generalized master curves according to the time-stress superposition principle (Equa-
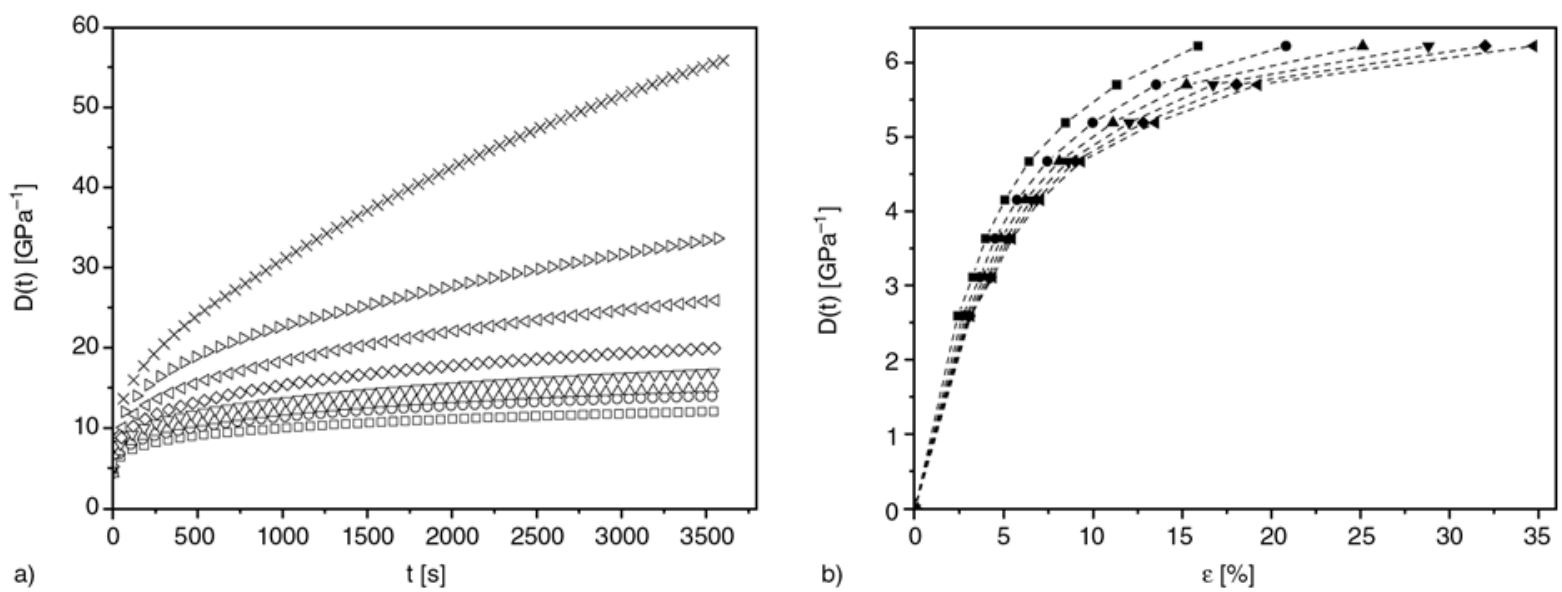

Figure 9. (a) Representative isothermal creep compliance curves of PE sample at various stress levels $\left(T=30^{\circ} \mathrm{C}\right)$, (口) $2.59 \mathrm{MPa},($ o) $3.11 \mathrm{MPa},(\Delta) 3.63 \mathrm{MPa},(\nabla) 4.15 \mathrm{MPa},(\diamond) 4.67 \mathrm{MPa},(\triangleleft) 5.19 \mathrm{MPa},(\triangleright) 5.70 \mathrm{MPa}$, (×) $6.22 \mathrm{MPa}$. (b) Isochronous curves of PE sample at different times $\left(T=30^{\circ} \mathrm{C}\right)$, (•) $600 \mathrm{~s},(\bullet) 1200 \mathrm{~s}$, (४) $1800 \mathrm{~s},(\boldsymbol{\nabla}) 2400 \mathrm{~s},(\diamond) 3000 \mathrm{~s},(\triangleleft) 3600 \mathrm{~s}$.
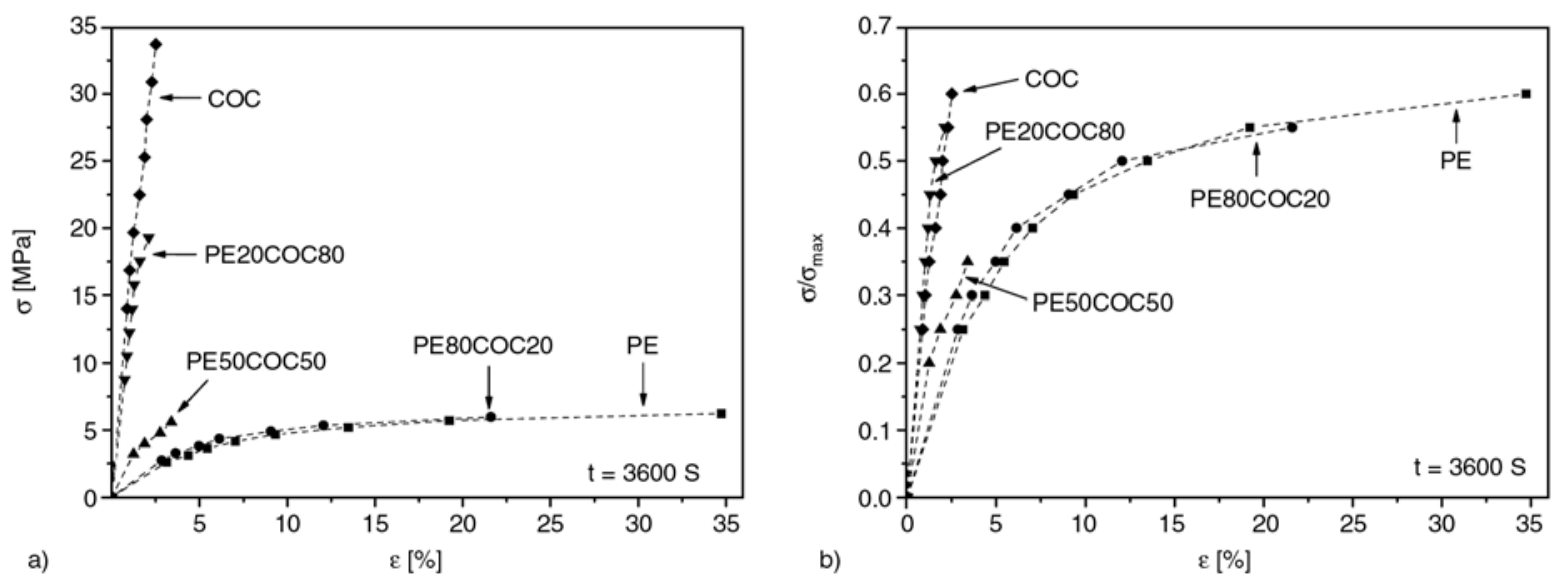

Figure 10. Isochronous curves at $3600 \mathrm{~s}$ of the $\mathrm{PE} / \mathrm{COC}$ blends from isothermal creep tests, (a) stress-strain isochronous curves, (b) relative stress-strain isochronous curves 


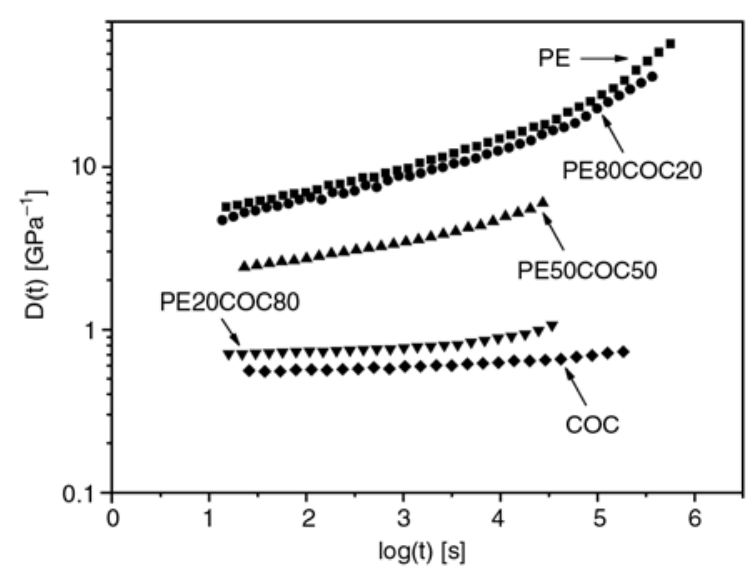

Figure 11. Isothermal creep compliance master curves of the $\mathrm{PE} / \mathrm{COC}$ blends according to time-stress superposition principle (see Equation (7)), $T_{0}=$ $30^{\circ} \mathrm{C}, \sigma_{0}=20 \% \cdot \sigma_{\max }$

tion (7)), starting from isothermal creep compliance data of neat components and of the related blends computed at different stress levels. Figure 11 reports creep compliance master curves of the prepared blends at $T=30^{\circ} \mathrm{C}$, considering a reference stress equal to the $20 \%$ of the yield strength detected in quasi-static tensile tests. Even in this case it can be concluded that the creep behaviour of the neat matrices is not substantially affected by the presence of the second component up to concentrations of $20 \mathrm{wt} \%$. Thus, master curve of neat LLDPE practically superimposes to that of PE80COC20 sample. Only for higher COC weight fractions the creep resistance of the blends is significantly improved by the introduction of a less compliant component.

\section{Conclusions}

Mechanical properties of LLDPE/COC heterogeneous blends prepared by melt mixing indicate poor interfacial adhesion despite the fact that physical interactions between the components are manifested by (i) increasing crystallinity of LLDPE with rising COC fraction, (ii) increasing $T_{\mathrm{g}}$ of $\mathrm{COC}$ with rising LLDPE fraction and (iii) SEM micrographs of fracture surfaces, which show that fracture frequently propagates through the particles and not along the $\mathrm{PE} / \mathrm{COC}$ interphase. These results were tentatively explained by (i) a partial incorporation of the ethylene segments of COC into the LLDPE crystalline phase and, consequently, (ii) increasing percentage of norbornene units in the remaining COC component undergoing the glass transition. The presence of $\mathrm{COC}$ in the blends promoted a rel- evant increase of the thermal degradation stability, especially when an oxidative atmosphere was considered. Quasi-static tensile tests showed that increasing fraction of $\mathrm{COC}$ in the blends accounts for an enhancement of the elastic modulus and a decrease in the strain at break, while tensile strength passes through a minimum. These results are in a good conformity with the model predictions based on the equivalent box model and equations provided by the percolation theory. Moreover, increasing fraction of $\mathrm{COC}$ in the blends increased the maximum load sustained by the samples in impact tests, but profoundly decreased the blend ductility. Concurrently, creep measurements demonstrated that a significant reduction of the creep compliance of LLDPE could be achieved only for the COC fractions exceeding $20 \mathrm{wt} \%$.

\section{Acknowledgements}

The last author (J. K.) is greatly indebted to the Grant Agency of the Czech Republic for financial support making the participation in this work possible (grant No. 106/09/ 1348).

\section{References}

[1] Folkes M. J., Hope P. S.: Polymer blends and alloys. Chapman and Hall, Cambridge (1993).

[2] Luettmer-Strathmann J., Lipson J. E. G.: Miscibility of polyolefin blends. Macromolecules, 32, 1093-1102 (1999).

DOI: $10.1021 / \mathrm{ma981478 \textrm {e }}$

[3] Olabisi O., Robenson L. M., Shaw M. T.: Polymerpolymer miscibility. Academic Press, New York (1979).

[4] Paul D. R., Bucknall C. B.: Polymer blends. Wiley, New York (1999).

[5] Arndt M., Beulich I.: $\mathrm{C}_{1}$-symmetric metallocenes for olefin polymerisation, 1 . Catalytic performance of $\left[\mathrm{Me}_{2} \mathrm{C}(3\right.$-tertBuCp)(Flu) $] \mathrm{ZrCl}_{2}$ in ethene/norbornene copolymerisation. Macromolecular Chemistry and Physics, 199, 1221-1232 (1998).

DOI: $10.1002 /($ SICI)1521-3935(19980601)199:6< $1221:: A I D-M A C P 1221>3.0 . C O ; 2-2$

[6] Donner M., Fernandes M., Kaminsky W.: Synthesis of copolymers with sterically hindered and polar monomers. Macromolecular Symposia, 236, 193-202 (2006).

DOI: 10.1002/masy.200690055

[7] Kaminsky W., Hoff M., Derlin S.: Tailored branched polyolefins by metallocene catalysis. Macromolecular Chemistry and Physics, 208, 1341-1348 (2007).

DOI: $10.1002 /$ macp. 200700053 
[8] Kaminsky W., Tran P. D., Werner R.: New polymers by copolymerization of ethylene and norbornene with metallocene catalysts. Macromolecular Symposia, 213, 101-108 (2004).

DOI: $10.1002 /$ masy.200450911

[9] Ruchatz D., Fink G.: Ethene-norbornene copolymerization using homogenous metallocene and half-sandwich catalysts: Kinetics and relationships between catalyst structure and polymer structure. 1 . Kinetics of the ethene-norbornene copolymerization using the [(isopropylide ne) $\left(\eta^{5}\right.$-inden-1-ylidene- $\eta^{5}$-cyclopentadienyl)]zirconium ndichloride/methylaluminoxane catalyst. Macromolecules, 31, 4669-4673 (1998).

DOI: $10.1021 / \mathrm{ma} 971041 \mathrm{r}$

[10] Ruchatz D., Fink G.: Ethene-norbornene copolymerization using homogenous metallocene and half-sandwich catalysts: Kinetics and relationships between catalyst structure and polymer structure. 2. Comparative study of different metallocene- and half-sandwich/methylaluminoxane catalysts and analysis of the copolymers by ${ }^{13} \mathrm{C}$ nuclear magnetic resonance spectroscopy. Macromolecules, 31, 4674-4680 (1998).

DOI: $10.1021 / \mathrm{ma} 971042 \mathrm{j}$

[11] Ruchatz D., Fink G.: Ethene-norbornene copolymerization with homogeneous metallocene and half-sandwich catalysts: Kinetics and relationships between catalyst structure and polymer structure. 3. Copolymerization parameters and copolymerization diagrams. Macromolecules, 31, 4681-4683 (1998). DOI: $10.1021 / \mathrm{ma} 971043 \mathrm{~b}$

[12] Ruchatz D., Fink G.: Ethene-norbornene copolymerization with homogeneous metallocene and half-sandwich catalysts: Kinetics and relationships between catalyst structure and polymer structure. 4. Development of molecular weights. Macromolecules, 31, 4684 4686 (1998).

DOI: $10.1021 / \mathrm{ma} 9710444$

[13] Tritto I., Boggioni L., Jansen J. C., Thorshaug K., Sacchi M. C., Ferro D. R.: Ethylene-norbornene copolymers from metallocene-based catalysts: Microstructure at tetrad level and reactvity ratios. Macromolecules, 35, 616-623 (2002).

DOI: $10.1021 / \mathrm{ma} 011365 \mathrm{~m}$

[14] Forsyth J., Pereña J. M., Benavente R., Pérez E., Tritto I., Boggioni L., Brintzinger H-H.: Influence of the polymer microstructure on the thermal properties of cycloolefin copolymers with high norbornene contents. Macromolecular Chemistry and Physics, 202, 614-620 (2001).

DOI: $10.1002 / 1521-3935(20010301) 202: 5<614:: A I D-$ MACP614>3.0.CO;2-C

[15] Forsyth J. F., Scrivani T., Benavente R., Marestin C., Pereña J. M.: Thermal and dynamic mechanical behavior of ethylene/norbornene copolymers with medium norbornene contents. Journal of Applied Polymer Science, 82, 2159-2165 (2001).

DOI: $10.1002 /$ app.2063
[16] Scrivani T., Benavente R., Pérez E., Pereña J. M.: Stress-strain behaviour, microhardness, and dynamic mechanical properties of a series of ethylene-norbornene copolymers. Macromolecular Chemistry and Physics, 202, 2547-2553 (2001).

DOI: 10.1002/1521-3935(20010801)202:12<2547:: AID-MACP2547>3.0.CO;2-X

[17] Kolařík J., Pegoretti A., Fambri L., Penati A.: Non-linear long-term tensile creep of poly(propylene)/cycloolefin copolymer blends with fibrous structure. Macromolecular Materials and Engineering, 288, 629-641 (2003).

DOI: $10.1002 /$ mame.200300005

[18] Pegoretti A., Kolařík J., Fambri L., Penati A.: Polypropylene/cycloolefin copolymer blends: Effects of fibrous phase structure on tensile mechanical properties. Polymer, 44, 3381-3387 (2003). DOI: 10.1016/S0032-3861(03)00248-9

[19] Kolař́ík J., Kruliš Z., Šlouf M., Fambri L.: High-density polyethylene/cycloolefin copolymer blends. Part 1: Phase structure, dynamic mechanical, tensile, and impact properties. Polymer Engineering and Science, 45, 817-826 (2005).

DOI: $10.1002 /$ pen.20337

[20] Kolařík J., Pegoretti A., Fambri L., Penati A.: Highdensity polyethylene/cycloolefin copolymer blends. Part 2: Nonlinear tensile creep. Polymer Engineering and Science, 46, 1363-1373 (2006).

DOI: $10.1002 /$ pen. 20580

[21] Pimbert S.: Evaluation of the fractionated crystallization of isotactic polypropylene and high density polyethylenes in their blends with cycloolefin copolymers. Macromolecular Symposia, 203, 277-283 (2003).

DOI: $10.1002 /$ masy.200351330

[22] Šlouf M., Kolařík J., Fambri L.: Phase morphology of $\mathrm{PP} / \mathrm{COC}$ blends. Journal of Applied Polymer Science, 91, 253-259 (2004).

DOI: $10.1002 / a p p .13253$

[23] Stricker F., Mülhaupt R.: Rubber-toughened cycloolefin copolymers. Die Angewandte Makromolekulare Chemie, 256, 101-104 (1998).

DOI: $10.1002 /($ SICI)1522-9505(19980401)256:1<101 $:: A I D-A P M C 101>3.0 . C O ; 2-4$

[24] Khanarian G.: Rubber toughened and optically transparent blends of cyclic olefin copolymers. Polymer Engineering and Science, 40, 2590-2601 (2000). DOI: 10.1002/pen.11389

[25] Durmuş A., Woo M., Kaşgöz A., Macosko C. W., Tsapatsis M.: Intercalated linear low density polyethylene (LLDPE)/clay nanocomposites prepared with oxidized polyethylene as a new type compatibilizer: Structural, mechanical and barrier properties. European Polymer Journal, 43, 3737-3749 (2007).

DOI: $10.1016 /$ j.eurpolymj.2007.06.019

[26] Hotta S., Paul D. R.: Nanocomposites formed from linear low density polyethylene and organoclays. Polymer, 45, 7639-7654 (2004).

DOI: $10.1016 /$ j.polymer.2004.08.059 
[27] Kontou E., Niaounakis M.: Thermo-mechanical properties of LLDPE/SiO $\mathrm{S}_{2}$ nanocomposites. Polymer, 47, 1267-1280 (2006).

DOI: 10.1016/j.polymer.2005.12.039

[28] Lew C. Y., Murphy W. R., McNally G. M.: Preparation and properties of polyolefin-clay nanocomposites. Polymer Engineering and Science, 44, 1027-1035 (2004).

DOI: 10.1002/pen.20096

[29] Niaounakis M., Kontou E.: Effect of LDPE on the thermomechanical properties of LLDPE-based films. Journal of Polymer Science B: Polymer Physics, 43, 1712-1727 (2005).

DOI: $10.1002 /$ polb.20473

[30] Bondioli F., Dorigato A., Fabbri P., Messori M., Pegoretti A.: High-density polyethylene reinforced with submicron titania particles. Polymer Engineering and Science, 48, 448-457 (2008).

DOI: $10.1002 /$ pen. 20973

[31] Osman M. A., Rupp J. E. P., Suter U. W.: Tensile properties of polyethylene-layered silicate nanocomposites. Polymer, 46, 1653-1660 (2005).

DOI: $10.1016 /$ j.polymer.2004.11.112

[32] Handge U. A., Okamoto K., Münstedt H.: Recoverable deformation and morphology after uniaxial elongation of a polystyrene/linear low density polyethylene blend. Rheologica Acta, 46, 1197-1209 (2007).

DOI: $10.1007 / \mathrm{s} 00397-007-0208-5$

[33] Liu Y., Shi Q., Ke Z., Yin L., Yin J.: Reactive compatibilization of LLDPE/PS blends with a new type of Lewis acid as catalyst. Polymer Bulletin, 63, 411-421 (2009).

DOI: 10.1007/s00289-009-0114-3

[34] Zhang H., Zhang Y., Guo W., Xu D., Wu C.: Thermal properties and morphology of recycled poly(ethylene terephthalate)/maleic anhydride grafted linear lowdensity polyethylene blends. Journal of Applied Polymer Science, 109, 3546-3553 (2008).

DOI: 10.1002/app.28456

[35] Zhang Y., Zhang H., Yu Y., Guo W., Wu C.: Recycled poly(ethylene terephthalate)/linear low-density polyethylene blends through physical processing. Journal of Applied Polymer Science, 114, 1187-1194 (2009). DOI: $10.1002 /$ app.30030

[36] Ismail H., Ahmad Z., Nordin R., Rashid A. R.: Processibility and miscibility studies of uncompatibilized linear low density polyethylene/poly(vinyl alcohol) blends. Polymer-Plastics Technology and Engineering, 48, 1191-1197 (2009). DOI: 10.1080/03602550903147379

[37] Su Z., Li Q., Liu Y., Xu H., Guo W., Wu C.: Phase structure of compatibilized poly(lactic acid)/linear low-density polyethylene blends. Journal of Macromolecular Science B: Physics, 48, 823-833 (2009). DOI: $10.1080 / 00222340902956327$
[38] Da Costa H. M., Ramos V. D.: Analysis of thermal properties and rheological behavior of LLDPE/EPDM and LLDPE/EPDM/SRT mixtures. Polymer Testing, 27, 27-34 (2008).

DOI: $10.1016 /$ j.polymertesting.2007.08.001

[39] Passaglia E., Coiai S., Giordani G., Taburoni E., Fambri L., Pagani V., Penco M.: Modulated crosslinking of polyolefins through radical processes in the melt. Macromolecular Materials and Engineering, 289, 809-817 (2004).

DOI: $10.1002 /$ mame.200400155

[40] Penco M., Della Sciucca S., Passaglia E., Giordani G., Coiai S., Di Landro L.: Effects of reactive melt mixing on the morphology and thermal behavior of linear lowdensity polyethylene/rubber blends. Journal of Applied Polymer Science, 109, 1014-1021 (2008).

DOI: 10.1002 app.28108

[41] Qin J., Ding H., Wang X., Xie M., Yu Z.: Blending LLDPE and ground rubber tires. Polymer-Plastics Technology and Engineering, 47, 199-202 (2008). DOI: $10.1080 / 03602550701816217$

[42] Sperling L. H.: Polymeric multicomponent materials: An introduction. Wiley, New York (1997).

[43] Utracki L. A.: Commercial polymer blends. Chapman and Hall, London (1988).

[44] Utracki L. A.: Polymer alloys and blends. Hanser, Munich (1990).

[45] Kopczynska A., Ehrenstein G. W.: Polymeric surfaces and their true surface tension in solids and melts. Journal of Materials Education, 29, 325-340 (2007).

[46] Kolař́́k J., Pegoretti A., Fambri L., Penati A.: Prediction of nonlinear long-term tensile creep of heterogeneous blends: Rubber-toughened polypropylene-poly (styrene-co-acrylonitrile). Journal of Applied Polymer Science, 88, 641-651 (2003).

DOI: 10.1002/app.11586

[47] Rana D., Lee C. H., Cho K., Lee B. H., Choe S.: Thermal and mechanical properties for binary blends of metallocene polyethylene with conventional polyolefins. Journal of Applied Polymer Science, 69, 2441-2450 (1998).

DOI: $10.1002 /(\mathrm{SICI}) 1097-4628(19980919) 69: 12<$ 2441::AID-APP15>3.0.CO;2-\#

[48] Lamnawar K., Vion-Loisel F., Maazouz A.: Rheological, morphological, and heat seal properties of linear low density polyethylene and cyclo olefine copolymer (LLDPE/COC) blends. Journal of Applied Polymer Science, 116, 2015-2022 (2010).

DOI: $10.1002 /$ app. 31804

[49] Van Krevelen D. W.: Properties of polymers: Their correlation with chemical structure; Their numerical estimation and prediction from additive group contributions. Elsevier, Amsterdam (1990).

[50] De Gennes P. G.: On a relation between percolation theory and the elasticity of gels. Journal de Physique Lettres, 37, 1-2 (1976).

DOI: 10.1051/jphyslet:019760037010100 
[51] Lyngaae-Jorgensen J., Kuta A., Sondergaard K., Poulsen K. V.: Structure and properties of polymer blends with dual phase continuity. Polymer Networks and Blends, 3, 1-13 (1993).

[52] Hsu W. Y., Wu S.: Percolation behavior in morphology and modulus of polymer blends. Polymer Engineering and Science, 33, 293-302 (1993). DOI: $10.1002 /$ pen.760330509

[53] Sax J., Ottino J. M.: Modeling of transport of small molecules in polymer blends: Application of effective medium theory. Polymer Engineering and Science, 23, 165-176 (1983). DOI: $10.1002 /$ pen. 760230310

[54] Kolařík J., Lednický F., Locati G. C., Fambri L.: Ultimate properties of polycarbonate blends: Effects of inclusion plastic deformation and of matrix phase continuity. Polymer Engineering and Science, 37, 128 137 (1997).

DOI: 10.1002/pen.11653

[55] Horák Z., Kolařík J., Šípek M., Hynek V., Večerka F.: Gas permeability and mechanical properties of polystyrene-polypropylene blends. Journal of Applied Polymer Science, 69, 2615-2623 (1998).

DOI: $10.1002 /($ SICI $) 1097-4628(19980926) 69: 13<$ 2615::AID-APP12>3.0.CO;2-T

[56] Kolařík J.: Simultaneous prediction of the modulus and yield strength of binary polymer blends. Polymer Engineering and Science, 36, 2518-2524 (1996). DOI: $10.1002 /$ pen. 10650

[57] Kolařík J.: Simultaneous prediction of the modulus, tensile strength and gas permeability of binary polymer blends. European Polymer Journal, 34, 585-590 (1998).

DOI: 10.1016/S0014-3057(97)00176-6

[58] Kolařík J., Fambri L., Pegoretti A., Penati A.: Prediction of the gas permeability of heterogeneous polymer blends. Polymer Engineering and Science, 40, 127131 (2000).

DOI: 10.1002/pen.11145

[59] Kolař́k J., Pegoretti A., Fambri L., Penati A.: Polypropylene/elastomer/poly(styrene-co-acrylonitrile) blends: Manifestation of the critical volume fraction of SAN in dynamic mechanical, tensile and impact properties. Journal of Polymer Research, 7, 7-14 (2000).

[60] Findley W. N., Lai J. S. Y.: A modified superposition principle applied to creep of nonlinear viscoelastic material under abrupt changes in state of combined stress. Journal of Rheology, 11, 361-380 (1967). DOI: 10.1122/1.549091

[61] Jazouli S., Luo W., Bremand F., Vu-Khanh T.: Application of time-stress equivalence to nonlinear creep of polycarbonate. Polymer Testing, 24, 463-467 (2005). DOI: $10.1016 /$ j.polymertesting.2005.01.002
[62] Brostow W.: Time-stress correspondence in viscoelastic materials: An equation for the stress and temperature shift factor. Materials Research Innovations, 3, 347-351 (2000).

DOI: $10.1007 / \mathrm{s} 100190000054$

[63] Luo W., Yang T-Q., An Q.: Time-temperature-stress equivalence and its application to nonlinear viscoelastic materials. Acta Mechanica Solida Sinica, 14, 195199 (2001).

[64] Schapery R. A.: On the characterization of nonlinear viscoelastic materials. Polymer Engineering and Science, 9, 295-310 (1969). DOI: $10.1002 /$ pen.760090410

[65] Yen S-C., Williamson F. L.: Accelerated characterization of creep response of an off-axis composite material. Composites Science and Technology, 38, 103-118 (1990). DOI: 10.1016/0266-3538(90)90001-L

[66] Saikrasun S., Limpisawasdi P., Amornsakchai T.: Effect of LCP and rPET as reinforcing materials on rheology, morphology, and thermal properties of in situ microfibrillar-reinforced elastomer composites. Journal of Applied Polymer Science, 112, 1897-1908 (2009).

DOI: $10.1002 /$ app.29715

[67] Saikrasun S., Saengsuwan S.: Thermal decomposition kinetics of in situ reinforcing composite based on polypropylene and liquid crystalline polymer. Journal of Materials Processing Technology, 209, 3490-3500 (2009).

DOI: 10.1016/j.jmatprotec.2008.08.005

[68] Thirtha V., Lehman R., Nosker T.: Morphological effects on glass transition behavior in selected immiscible blends of amorphous and semicrystalline polymers. Polymer, 47, 5392-5401 (2006).

DOI: $10.1016 /$ j.polymer.2006.05.014

[69] Thirtha V. M., Lehman R. L., Nosker T. J.: Glass transition phenomena in melt-processed polystyrene/polypropylene blends. Polymer Engineering and Science, 45, 1187-1193 (2005). DOI: 10.1002/pen.20387

[70] Brostow W., Lobland H., Narkis M.: Sliding wear, viscoelasticity, and brittleness of polymers. Journal of Material Research, 21, 2422-2428 (2006).

DOI: $10.1557 /$ JMR.2006.0300

[71] Brostow W., Lobland H. E. H.: Brittleness of materials: Implications for composites and a relation to impact strength. Journal of Material Science, 45, 242-250 (2010).

DOI: $10.1007 / \mathrm{s} 10853-009-3926-5$

[72] Kolařík J., Pegoretti A.: Non-linear tensile creep of polypropylene: Time-strain superposition and creep prediction. Polymer, 47, 346-356 (2006).

DOI: $10.1016 /$ j.polymer.2005.11.013 